\title{
General Equilibrium of an Ecosystem
}

\author{
John Tschirhart* \\ Department of Economics and Finance \\ University of Wyoming \\ Laramie, Wyoming 82071
}

Appeared in the Journal of Theoretical Biology, March 2000.

*This research was supported by a U.S. Environmental Protection Agency grant, \#R 826281-01-0, and by the State of Wyoming. I thank two anonymous referees, Tom Crocker, Rudi Pethig, David Finoff, Steve Gloss, Greg Hayward, Wayne Hubert, Steve Swallow, Bob Hall and seminar participants at the University of Florida, the Pacific Northwest Conference on Environmental \& Resource Economics, the University of Oregon, the U.S. Forest Service, Ft. Collins, Colorado, and a conference on integrating economics and ecosystems, University of Wyoming. Any errors and omissions in the paper are my responsibility. 


\section{Introduction}

A growing human population and its increasing consumption of natural resources threaten the earth's ecosystems, and the loss of ecosystems threatens the growing human population and its increasing consumption. (E.g., see Daily, 1997) These mutual threats exist because human economies and natural ecosystems are inextricably linked: common economic variables such as incomes and prices affect and are affected by common ecosystem variables such as resiliency and species populations. In spite of the linkages between the two systems, models of economies and ecosystems largely disregard one another. Bioeconomic models that do merge economic and ecosystem concepts tend to address isolated markets and very few species. They do not address the myriad ways in which changes in an economy influence ecosystem functions, and in turn how changes in ecosystem functions feedback to the economy.

At all government levels, numerous policies are formulated and implemented based on economic models which range from simplistic to sophisticated. The latter assume certain behavior on the part of human consumers and firms, and they describe outcomes in terms of prices, wages and incomes. If policy makers give any thought at all to the impact their policies will have on surrounding ecosystems, typically it is qualitative and addresses neither how the impacted ecosystems will alter the outcomes from the economic model, nor how humans will respond to these new outcomes, alter their behavior, and further impact the ecosystems. For example, Arrow et al. (1995) state:

"In areas where the environment is beginning to impinge on policy, as in the General Agreement on Tariffs and Trade (GATT) and the North American Free Trade Agreement (NAFTA), it remains a tangential concern, and the presumption is often made that economic growth and economic liberalization are, in some sense, good for the environment." (p. 520)

Developing policies with quantitative economic analysis and qualitative ecosystem analysis allows for considerable latitude in interpretation, and may result in discounting the impacts on the ecosystem because of their subjective nature. However, if the ecosystems can be integrated with the economic models, the mutual dependencies and the human responses can be taken into account, and 
the impacts on the ecosystems can be quantified in terms of ecosystem variables such as species populations, and in terms of economic variables such as prices and incomes. ${ }^{\mathrm{i}}$

In this paper, quantifying impacts on ecosystems is assumed to be desirable: improved policies will follow from models that incorporate both economies and ecosystems. ${ }^{\text {ii }}$ Because models of economies already exist and are widely used, a fruitful approach is to develop an ecosystem model that is compatible with these economic models, yet captures the salient biological features. Extant economy models are referred to as general equilibrium models and they may include thousands of consumers and firms whose decisions are manifested in demands for and supplies of consumer goods. Ecosystems comprise thousands of organisms, and the goal here is to develop a general equilibrium ecosystem model that yields organisms' demands for and supplies of biomass, and to design the model in a way that allows it to be integrated with a general equilibrium model of an economy.

Besides the benefit of improved policymaking, a general equilibrium ecosystem model also can prove useful in addressing purely biological issues. For examples, economic models are used to investigate substitutability between inputs: If a tax on capital is increased, how will this effect the capital/labor ratio employed by firms? Similarly, with a general equilibrium ecosystem model: If an ecosystem incurs habitat destruction, how will predator-prey populations be altered? Other authors have used metapopulation models to address the same question (Bascompte and Sole, 1998). Economic models are used to investigate economic stability: If a policy causes a change in the number of firms in a market, how will this impact economic performance? Similarly, with a general equilibrium ecosystem model: If the functional diversity of an ecosystem is changed through habitat modification, how will this impact ecosystem processes? Because all species are not equal, the loss of certain species may impact ecosystem process significantly more than other species (Tilman, et al., 1997). An ecosystem model could be used to help identify and value "keystone" species. With 
respect to preserving endangered species, the importance of saving entire ecosystems as opposed to individual species has become apparent (Leader-Williams, 1990; Derrickson \& Snyder, 1992; and Snyder et al., 1996; Beissinger and Perrine, 2000). With a combined ecosystem/economic model, the cost savings and effectiveness of multi-species recovery programs can be identified.

\section{General Equilibrium Models}

In general equilibrium models of economies there are two types of agents: consumers and firms. The consumers are assumed to maximize their well being, or utility, where utility derives from goods purchased from firms. Consumers can purchase these goods using their income received from selling their endowments of resources (labor, capital and natural resources) to the firms. The firms combine the consumers' resources, or inputs, in production processes that yield goods. Firms are assumed to maximize their profits, or the difference between revenues from the goods they sell and expenditures on the resources they purchase. Thus, there is a flow of inputs from consumers to firms, and a flow of goods from firms to consumers. Money flows circularly in the reverse direction, consumers spend their income providing revenue to the firms, and the firms purchase inputs providing income to consumers.

Every good and every input is traded in a market characterized by demand and supply. In a market for a good, demand is the sum of all individual consumer demands, where the individual demands are derived from the consumer utility maximization behavior. Supply is the sum of all firms' supplies, where the supplies are derived from the firms' profit maximization behavior. A market for inputs is similar, with the consumers and firms in reverse positions. A general equilibrium is defined as a state where all consumers are maximizing their utilities, all firms are maximizing their profits, and demand equals supply in every market.

Prices of both goods and inputs play a central role in the general equilibrium model. Marketclearing prices are those that equate demands and supplies. Individual consumers and firms have no 
control over prices as each is only one agent among many and, therefore, has an imperceptible influence on the market. When maximizing their utility (profit), consumers (firms) take prices as signals of the relative scarcity of goods (inputs). The mathematical problem is to find a set of market-clearing prices that will support a general equilibrium.

In recent years, theoretical general equilibrium models have moved from abstract representations of economies to realistic applied general equilibrium (AGE) models that employ data on consumer and firm characteristics to evaluate policy options (Shoven and Whalley, 1984). Computers allow much detail and complexity so that geographic regions with millions of consumers and hundreds of firms from many different industries are included. Important questions about how the feedback effects of tax, trade or environmental policies on prices, wages and employment are addressed.

Unfortunately, AGE models of economies fall woefully short of addressing many environmental issues, particularly where ecosystems are concerned. AGE models address neither the feedback effects of economic activity on ecosystems, nor the feedback effects that disturbed ecosystems have on economies. What is needed is to link AGE models of economies with general equilibrium models of ecosystems so that the critical interactions of the two systems are accounted for when developing policies. The first step in such a linkage is to develop a general equilibrium ecosystem model that is both biologically sound and flexible enough to be combined with its economic counterpart.

The more similar are our interpretations of the economic and ecosystems, the easier their integration will be. In economies, the agents are consumers and firms both of whom demand material from and supply material to other consumers and firms. In ecosystems the agents are members of species who demand biomass from and supply biomass to members of other species. In the economy, money is the unit of exchange; in the ecosystem, energy can be used as a unit of 
exchange. In the economy, consumers and firms are assumed to optimize: consumers maximize utility, firms maximize profit. In the ecosystem, optimization will be assumed: individual organisms maximize their net energy intake as discussed below.

Yet, there are key differences between economies and ecosystems that will require significant alterations to existing economic models. For examples, in a marketplace trade, material and money flow in opposite directions, but in an ecosystem trade, biomass and energy flow in the same direction. In the economy overall, material flows one way from consumers as owners of natural resources, to firms, who transform the natural resources into goods, to consumers who eventually dispose of the material (although some of the material is recycled back to firms). At the same time, money flows circularly in the opposite direction of the materials. In the ecosystem, both biomass and energy flow one way from species in lower trophic levels to species in higher trophic levels. Some elements such as nitrogen do flow circularly in the ecosystem, although these cycles are not modeled here. ${ }^{\text {iii }}$ In an economy, consumers or firms typically pay the same money price to other firms for the latter's goods, but in an ecosystem organisms from different predator species pay different energy prices to capture biomass from a prey species. Other differences will become evident as the ecosystem AGE model is developed below.

In the ecosystem modeled here, each organism maximizes net energy intake given the energy prices it must "pay" to obtain biomass from other organisms. Whether energy is an appropriate objective is subject to debate, and other objectives such as exergy (Jorgensen, 1982, 1986) or ascendancy (Ulanowicz, 1980) have been proposed. ${ }^{\text {iv }}$ However, energy maximization has its roots in Lotka (1922), was formalized in a manner similar to that used here by Hannon (1973, 1976, 1979), and according to Herendeen (1991) has been the most frequently chosen maximand. Hannon refers to the net energy intake as stored energy; however, to emphasize that this energy intake is a flow, the term used herein is net energy. Net energy maximization yields each 
organism's demands for biomass from other organisms, and the demands are aggregated over all organisms within each species to build the biomass market demands and market supplies. An equilibrium occurs when market demands for each species' biomass are equated to the supply of that species biomass at some set of energy prices. Although no one organism has any control over these prices, the total number of organisms and their demands and supplies determine the prices through exchanges of biomass. In this paper there is no human intervention and the total energy available in the system is from the sun.

The importance of incorporating optimizing behavior needs to be stressed. ${ }^{\mathrm{v}}$ From the optimization problem comes an organism's biomass demands for other species. These demands are functions of the energy prices that must be paid to capture biomass. As energy prices change, demands will change; generally, lower (higher) prices will mean higher (lower) demands. Thus, the model captures the key concept that organisms switch or substitute among prey as their environment changes. ${ }^{\mathrm{vi}}$ If the ecosystem in not in equilibrium because demands and supplies are not equated in all biomass markets, energy prices adjust until an equilibrium is reached. The mechanism driving the system to equilibrium is substitution. As prices adjust, organisms make substitutions and, thereby, change their demands and supplies.

Early AGE economic models used input/output techniques which, while useful and still in use, have important limitations. Besides using only linear relationships, there is no consumer or firm optimization: consumer demands are given, and on the supply side firms are not able to change input ratios through substitution in response to price changes. Similarly, energy based input/output ecosystem models (e.g., Hannon, 1973) have the same limitations. Although they account for energy flows, the organisms in the system do not substitute in response to energy price changes. ${ }^{\text {vii,viii }}$ A few authors have brought environmental issues into general equilibrium models to highlight the 
importance of conservation of mass and the time behavior of the system, although ecosystems are not explicitly considered. (For an example and references, see Perrings (1989).)

By allowing for individual demands and substitution, the AGE model below essentially combines optimal foraging strategy models of individual organisms into an ecosystem wide model wherein the interplay of numerous foraging strategies are combined. The foraging strategies adjust with changing energy prices moving the system toward equilibrium.

Before developing the model, the concept of equilibrium warrants further comment. That a complex system may attain an equilibrium is disputed, perhaps more so in biology than in economics. As already indicated, in the latter field work on AGE models continues and many recent contributions are explained theoretically and demonstrated with applications in Ginsburgh and Keyzer (1997). Analysts who employ equilibrium models presumably do not harbor the illusion that they have grasped reality or that an equilibrium actually is attained. At best, equilibrium is a moving target, constantly being perturbed, that an economy or an ecosystem may be groping toward. The unreal assumptions made in economic models, chiefly the construct of perfectly competitive markets, is often attacked as unrealistic, and much work has been done to relax the competitive assumption by adding institutional richness, some of which is described by Landa (1999). However, to argue that an economic or ecosystem general equilibrium model is unrealistic misses the point. The model is a tool for gaining insight into the system, and if the model predicts reasonably well it is a useful tool. ${ }^{\text {ix }}$

\section{The Individual Organism}

The model is nonstochastic and time is omitted. Omitting time eliminates interesting dynamic aspects such as age structure issues, but it is necessary for tractability and to be consistent with AGE models. The ecosystem comprises $m$ species in a food web. The species, indexed $1, \ldots$, $\mathrm{m}$, are arranged such that members of higher numbered species may prey on members of a lower 
numbered species, but not vice versa. If members of species i prey on members of species $\mathrm{j}, \mathrm{i}>\mathrm{j}$, species $\mathrm{i}$ is said to demand biomass from species $\mathrm{j}$, which supplies biomass. The transfer of biomass is said to take place in an ecosystem market, and if there are $\mathrm{m}$ species in total, there are at most

$$
\sum_{i=1}^{m-1}
$$

active markets. Because all energy in the system originates with the sun which is indexed by 0 , and all species can potentially "prey" on the sun, this increases the maximum possible number of markets to

$$
\sum_{\mathrm{i}=1}^{\mathrm{m}} \mathrm{i}
$$

Assumption 1: Each organism behaves as if it is a net energy maximizer where net energy is the difference between energy inflows and outflows.

A general expression for the net energy of a representative organism from species $i$ be given

by:

$$
R_{i}=\left[e_{0}-e_{i 0}\right] x_{i 0}+\sum_{j=1}^{i-1}\left[e_{j}-e_{i j}\right] x_{i j}-\sum_{k=i+1}^{m} e_{i j} y_{i k}-f^{i}\left(\sum_{j=0}^{i-1} x_{i j}\right)-\beta_{i}
$$

where the e terms are in energy units (e.g., kilocalories) per biomass units and the $\mathrm{x}$ and $\mathrm{y}$ are in biomass units (e.g., kilograms). The first term on the right side of (3) is the incoming energy from the sun. The $e_{0}$ is the solar energy fixed for each unit of biomass, $x_{i 0}$, that the member of species $i$ produces in photosynthesis, and the $\mathrm{e}_{\mathrm{i} 0}$ is the energy spent to fix $\mathrm{e}_{0}$. The energies will vary across species, as, for example, with variations in plants' abilities to open their stomata in low light intensities (Chazdon and Pearcy, 1986). The second term on the right side of (3) is the inflow of energy from organisms of other species to species $i$. The $e_{j}$ is the energy embodied in a unit of biomass from a member of species $\mathrm{j}, \mathrm{e}_{\mathrm{ij}}$ is the energy the member of species $\mathrm{i}$ must spend to locate and capture a unit of biomass of species $\mathrm{j}$, and $\mathrm{x}_{\mathrm{ij}}$ is the biomass transferred from the member of 
species $\mathrm{j}$ to the member of species $\mathrm{i}$. The third term is the outflow of energy to members of species that prey on $\mathrm{i}$. The $\mathrm{e}_{\mathrm{i}}$ is the embodied energy in a unit of biomass from a member of species $\mathrm{i}$, and $\mathrm{y}_{\mathrm{ij}}$ is the biomass supplied by i to $\mathrm{k}$. The fourth and fifth terms represent respiration which is energy lost by the ecosystem to the atmosphere. Respiration is divided into two parts, the $\mathrm{f}^{\mathrm{i}}(\bullet)$ which depend on energy intake and includes feces, reproduction, defending territory, etc. ${ }^{\mathrm{x}}$ Assuming differentiability,

$$
\frac{\partial \mathrm{f}^{\mathrm{i}}(\cdot)}{\partial \mathrm{x}_{\mathrm{ij}}}>0, \text { for } \mathrm{i}, \mathrm{j}=1, \ldots \mathrm{m}, \mathrm{j}>\mathrm{i}
$$

The second part of respiration, $\beta_{\mathrm{i}}$, is basal metabolism and it is independent of energy intake.

The embodied energy terms, $\mathrm{e}_{\mathrm{i}}$, are constants and assumed to be invariant. The energies spent in predation, the $\mathrm{e}_{\mathrm{ij}}$, are the energy prices referred to in Section II. These energy prices play a central role in the maximization process, because an organism's choice of prey will depend on the relative energy prices it pays. Prey preference has been examined elsewhere (See Gutierrez (1996) for a summary.) and predators are assumed to prefer one prey over another according to indices based on relative densities of the prey species. The model presented here is behaviorally more fundamental in that a predator's choices do not depend on its taking an inventory of available prey species to determine densities; instead, a predator's choices depend on how much energy will be lost in locating and capturing one prey versus another. Of course, the energy prices the predator must pay likely depends on densities, but densities are accounted for in the AGE model through the equilibrium conditions involving many species, and not in the organisms' individual maximization problems. Thus, to each organism the energy prices are exogenous: the organism has no control over the price paid to capture prey, because it is only one among many members of the predator species capturing only one of many members of the prey species. However, within the ecosystem 
the prices are endogenous, being determined in the biomass markets by demand and supply interactions.

In maximizing (3), the organism would prefer to supply zero biomass $\left(\mathrm{y}_{\mathrm{ij}}=0\right)$ to other organisms since outflows reduce net energy. However, an organism can supply zero biomass only if it demands zero biomass in the sense that to capture prey biomass the organism exposes itself to capture by other predator organisms, and the more biomass an organism captures the more it is exposed and the more biomass it supplies to predators. Owing to this predation risk the organism faces a tradeoff between foraging gains and losses (Lima and Dik, 1990).

Assumption 2: Organisms are subject to predation risk and the biomass they supply depends on the biomass they demand:

$$
y_{i k}=y_{i k}\left(\sum_{j=0}^{i-1} x_{i j}\right), \text { for } i=1, \ldots, m \text {, }
$$

and assuming differentiability,

$$
\frac{\partial \mathrm{y}_{\mathrm{ik}}(\cdot)}{\partial \mathrm{x}_{\mathrm{ij}}}>0, \text { for } \mathrm{i}, \mathrm{j}, \mathrm{k}=1, \ldots, \mathrm{m}, \mathrm{j}<\mathrm{i}<\mathrm{k}
$$

A problem of interpretation arises in the maximization problem, because once a member of species $\mathrm{i}$ is successfully preyed upon, it is gone. No further maximization takes place for this member. To avoid this discrete, zero/one problem, the maximization problem is assumed to represent the 'average' member of species i. Thus, when the organism is captured it does not lose its entire biomass, but rather it loses biomass equal to the mean loss over all members of its species. ${ }^{\mathrm{xi}}$

Not all organisms' maximization problems will contain all the terms in (3). For examples, autotrophs typically will prey only on the sun so the second term on the right side of (3) would vanish. Top predators typically do not prey on the sun, and the first term in (3) would vanish. A complete ecosystem also will contain microflora decomposers which prey on virtually all species, 
including top predators. The size of the food web will determine the values of $\mathrm{i}, \mathrm{j}$ and $\mathrm{k}$ and the number of biomass markets.

The representative member of species $\mathrm{i}, \mathrm{i}=1, \ldots, \mathrm{m}$, behaves as if it maximizes expression (3) over all its demands, $x_{i j}, j=0, \ldots, i-1$. The necessary first-order conditions for a maximum include:

$$
\begin{gathered}
{\left[e_{0}-e_{i 0}\right]-\sum_{k=i+1}^{m} e_{i} \frac{\partial y_{i k}}{\partial x_{i 0}}-\frac{\partial f^{i}}{\partial x_{i 0}}=0} \\
{\left[e_{j}-e_{i j}\right]-\sum_{k=i+1}^{m} e_{i} \frac{\partial y_{i k}}{\partial x_{i j}}-\frac{\partial f^{i}}{\partial x_{i j}}=0, \text { for } j=1, \ldots, i-1}
\end{gathered}
$$

Conditions (7) and (8) state that a maximum is achieved when the marginal benefits of predation equal the marginal costs of predation. More specifically, the organism maximizes net energy by setting the marginal energy received from predation (the first terms in (7) and (8)) equal to the marginal energy lost through predation, where the loss is a result of predation risk (second terms) and respiration activities (third terms).

Expressions (7) and (8) also lay out the conditions for predator substitution between prey species. For example, let $\mathrm{i}=6$ and $\mathrm{j}=4$ and 5 which implies two type (8) equations in which a predator from species 6 preys on members of species 4 and 5 and is preyed upon by members of species 7. Dividing one of the equations by the other and rearranging yields:

$$
\frac{\mathrm{e}_{4}-\mathrm{e}_{64}}{\mathrm{e}_{5}-\mathrm{e}_{65}}=\frac{\mathrm{e}_{6} \frac{\partial \mathrm{y}_{67}}{\partial \mathrm{x}_{64}}+\frac{\partial \mathrm{f}^{6}}{\partial \mathrm{x}_{64}}}{\mathrm{e}_{6} \frac{\partial \mathrm{y}_{67}}{\partial \mathrm{x}_{65}}+\frac{\partial \mathrm{f}^{6}}{\partial \mathrm{x}_{65}}}
$$

The left side of (9) is the ratio of marginal net energy gains from preying on species 4 and 5 , and the right side is the ratio of marginal energy losses from being preyed upon and from respiration. At the maximum, the representative organism in species 6 equates the ratio of marginal gains to the ratio 
of marginal losses. If these ratios are unequal, say after an external shock to the ecosystem leaves the left side of (9) greater than the right side of (9), then members of species 6 will substitute by preying more on species 4 and less on species 5, because the marginal return from 4 becomes greater than the marginal return from 5. More detail on interpreting these conditions appears in Hannon (1976), Tschirhart and Crocker (1987) or Crocker and Tschirhart (1992).

Assuming the second-order conditions for a maximum are satisfied, ${ }^{\text {xii }}$ the first-order conditions can be solved for the $\mathrm{x}_{\mathrm{ij}}$ as functions of the energy prices to yield $\mathrm{i}$ 's demands:

$$
\mathrm{x}_{\mathrm{ij}}\left(\mathbf{e}_{\mathrm{i}}\right) \equiv \mathrm{x}_{\mathrm{ij}}\left(\mathrm{e}_{\mathrm{i} 0}, \ldots, \mathrm{e}_{\mathrm{i}, \mathrm{i}-1}\right), \text { for } \mathrm{j}=0, \ldots, \mathrm{i}-1
$$

where the boldface $\mathbf{e}_{\mathbf{i}}=\left(\mathrm{e}_{\mathrm{i} 0}, \ldots, \mathrm{e}_{\mathrm{i}, \mathrm{i}-1}\right)$ is a vector of energy prices. The demands are also functions of the $e_{i}$, but these energy terms are constants and are suppressed in (10) for brevity. Substituting these demands into the $y_{\mathrm{ik}}$ yields the representative member i's supplies:

$$
\mathrm{y}_{\mathrm{ik}}\left(\mathbf{x}_{\mathbf{i}}\left(\mathbf{e}_{\mathbf{i}}\right)\right) \equiv \mathrm{y}_{\mathrm{ik}}\left(\mathrm{x}_{\mathrm{i} 0}\left(\mathrm{e}_{\mathrm{i} 0}, \ldots, \mathrm{e}_{\mathrm{i}, \mathrm{i}-1}\right), \ldots, \mathrm{x}_{\mathrm{i}, \mathrm{i}-1}\left(\mathrm{e}_{\mathrm{i} 0}, \ldots, \mathrm{e}_{\mathrm{i}, \mathrm{i}-1}\right)\right), \text { for } \mathrm{k}=\mathrm{i}+1, \ldots \mathrm{m}
$$

where the boldface $\mathbf{x}_{\mathbf{i}}=\left(\mathrm{x}_{\mathrm{i} 0}, \ldots, \mathrm{x}_{\mathrm{i}, \mathrm{i}-1}\right)$ is a vector of demands.

Using standard comparative static analysis, the effect of price changes on the organism's optimum demands can be determined. ${ }^{\text {xii }}$ Of particular importance is the "law of demand", as the energy price the organism pays to capture prey increases (decreases), the demand for the prey decreases (increases):

$$
\frac{\partial \mathrm{x}_{\mathrm{ij}}}{\partial \mathrm{e}_{\mathrm{ij}}} \prec 0
$$

for all $\mathrm{i}=1, \ldots, \mathrm{m}$ and $\mathrm{j}<\mathrm{i}$.

\section{Short-Run and Long-Run Equilibrium}

The short run is defined as that time over which the populations of all species are constant. In a short-run equilibrium, demand equals supply in every biomass market and a representative organism and its species may have negative, zero or positive net energy at the maximum. Nonzero 
net energy is not stable over the long run, however. Positive (negative) net energy is associated with greater (lesser) fitness and an increasing (decreasing) population. In the long run, populations of species are variable; they adjust to move toward a long-run equilibrium in which all organisms have zero net energy and the short-run equilibrium conditions hold. Although he does not model it explicitly, Hannon (1976) refers to this long-run equilibrium as a system steady state. ${ }^{\text {xiv }}$

Consider first the short run. The maximum number of biomass markets is given by (2). Each representative member's maximization problem yields, at most, i first-order conditions, i demands, and $\mathrm{m}$ - $\mathrm{i}$ supplies. In addition, there are $\mathrm{m}$ supplies from the sun so overall there is a demand and supply for each market. But these demands and supplies are for given energy prices, and there is no guarantee that at these prices demand equals supply in every market.

To find a set of prices that equates each demand with its associated supply, equilibrium equations are needed, one for each price to be determined. The equilibrium condition in a (non solar) market is constructed by equating the sum of all the predator organisms' demands with the sum of all the prey organisms' supplies. Because each organism in (3) is assumed to be a representative organism from that species, all organisms in each species are identical; therefore, to obtain the demand and supply sums multiply the representative organism's demands and supplies by the population of the species. Let $\mathrm{N}_{\mathrm{i}}$ be the population of species $\mathrm{i}$, then the equilibrium conditions are:

$$
\mathrm{N}_{\mathrm{i}} \mathrm{x}_{\mathrm{ij}}\left(\mathbf{e}_{\mathrm{i}}\right)=\mathrm{N}_{\mathrm{j}} \mathrm{y}_{\mathrm{ji}}\left(\mathbf{x}_{\mathrm{j}}\left(\mathbf{e}_{\mathrm{j}}\right)\right)
$$

for $i=2, \ldots, m$ as $j=1, \ldots, i-1$. There is one condition for each market, and the number of markets is given in (1). The left side of (13) is the total demand of species $i$ for species $j$, and the right side is the total supply of species $\mathrm{j}$ to species $\mathrm{i}$.

The solar markets wherein primary producers prey on the sun are treated differently, because the sun as prey does not supply energy in response to prices. The sun's supply is assumed to 
be limitless which is consistent with instances when primary producers only fix a small fraction of the solar energy striking the earth's surface. Despite this availability of limitless energy, primary producers do not increase their demand for solar energy beyond some finite amount owing to both increasing respiration losses and the price, $\mathrm{e}_{\mathrm{i} 0}$, they pay for energy. Moreover, primary producers usually are stationary and the price they pay for solar energy may depend on their species population in its vicinity owing to competition for sunlight. Given these considerations, the solar market prices are determined in accordance with Assumption 3:

Assumption 3: The energy price paid by an organism in primary producer species i, that given by $\mathrm{e}_{\mathrm{i} 0}$, is a function of the population of the primary producer; is, $\mathrm{e}_{\mathrm{i} 0}=\mathrm{e}_{\mathrm{i} 0}\left(\mathrm{~N}_{\mathrm{i}}\right)$.

If inter-species or intra-species competition or abiotic factors limit the sun's energy, this could be appended to the model by making the prices in Assumption 3 a function of other species' populations or the abiotic factors.

The equilibrium condition for any single market can be used to investigate how changes in populations will effect energy prices in a partial equilibrium setting. Let

$$
\mathrm{F}\left(\mathbf{e}_{\mathrm{i}}\right) \equiv \mathrm{N}_{\mathrm{i}} \mathrm{x}_{\mathrm{ij}}\left(\mathbf{e}_{\mathrm{i}}\right)-\mathrm{N}_{\mathrm{j}} \mathrm{y}_{\mathrm{ji}}\left(\mathbf{x}_{\mathrm{j}}\left(\mathbf{e}_{\mathrm{j}}\right)\right)=0
$$

and using the implicit function theorem:

$$
\begin{gathered}
\frac{\partial e_{i j}^{*}}{\partial N_{i}}=-\frac{\partial F / \partial N_{i}}{\partial F / \partial e_{i j}}=-\frac{x_{i j}}{N_{i} \partial x_{i j} / \partial e_{i j}}>0 \\
\frac{\partial e_{i j}^{*}}{\partial N_{j}}=-\frac{\partial F / \partial N_{j}}{\partial F / \partial e_{i j}}=-\frac{-y_{j i}}{N_{i} \partial x_{i j} / \partial e_{i j}}<0
\end{gathered}
$$

Figure 1 depicts these results for equilibrium in a single biomass market. Species i's demand for biomass of species $\mathrm{j}$ is the negatively sloped curve, and species j's supply is the vertical curve. Equilibrium price and quantity are $\mathrm{e}_{\mathrm{ij}}{ }^{*}$ and $\mathrm{N}_{\mathrm{i}} \mathrm{x}_{\mathrm{ij}}{ }^{*}$ respectively. The curves indicate that an increase in the population of species i shifts the demand curve to the right and the new equilibrium price 
would be greater than $\mathrm{e}_{\mathrm{ij}}{ }^{*}$ because of the greater predator competition. Alternatively, an increase in the population of species $\mathrm{j}$ shifts the supply curve to the right and the new equilibrium price would be lower than $\mathrm{e}_{\mathrm{ij}}{ }^{*}$ because of the greater prey density.

Finding a set of energy prices that yields a short-run equilibrium is a matter of simultaneously solving the first-order conditions from (3) and the equilibrium conditions from (13) for the demands and the energy prices. The number of demands and first-order conditions is given by (2), and the number of energy prices and equilibrium conditions is given by (1), so the number of equations equals the number of variables. Theoretical conditions on the functional forms of the net energy functions that guarantee a solution exists are not explored here, although in the simulations below solutions are provided for specific cases.

A system in short-run equilibrium moves toward long-run equilibrium through adjustments in the populations.

Assumption 4: The population of a species exhibiting positive (negative, zero) net energy increases (decreases, remains the same).

Population changes will set into motion forces that will move the species toward zero net energy. For instance, suppose a species has positive net energy and its population increases. This increase lowers the energy price predators must pay to capture species' members, because the species is more plentiful. Predators' demands for the species will increase by (12), the species' supply to predators will increase, and net energy will decrease. In addition, the price the species must pay for its prey will increase as there is more intra-species competition when the species' population grows. This price movement will also reduce the species' net energy as the species demands less prey, a result that follows by applying the envelope theorem to $(3) .{ }^{\mathrm{xv}}$ For a species with negative net energy in short-run equilibrium, the prices move in the opposite directions, and again the species moves toward zero net energy. 
Many methods for adjusting the populations could be introduced at this point, and different methods might be employed for different species. If abiotic environmental factors, threshold densities, clumping of populations or other factors are important, they could be introduced as well. Population adjustments are made using the well-known Verhulst-Pearl logistic equation:

$$
\mathrm{dN} / \mathrm{dt}=\mathrm{r} \mathrm{N}[1-\mathrm{N} / \mathrm{K}]
$$

where $\mathrm{r}$ is a growth rate and $\mathrm{K}$ is carrying capacity or the upper limit on growth. Consider the ith species with maximum net energy function given by $\mathrm{R}_{\mathrm{i}}\left(\mathrm{x}_{\mathrm{ij}}\left(\mathbf{e}_{\mathrm{i}}\right) ; \mathbf{N}^{\mathrm{t}}\right)=\mathrm{R}_{\mathrm{i}}(\cdot)$ which is obtained by substituting the optimum demands as functions of energy prices into the objective function in (3). $\mathbf{N}^{\mathrm{t}}$ is a vector of all species' populations and it appears in $\mathrm{R}_{\mathrm{i}}(\cdot)$ to indicate that net energies in time period t depend on populations in time period t. According to (17), the population will increase (decrease) if $\mathrm{N}_{\mathrm{i}}<(>) \mathrm{K}_{\mathrm{i}}$; therefore, using Assumption 4:

$$
\mathrm{R}_{\mathrm{i}}(\cdot)>0 \Rightarrow \mathrm{N}_{\mathrm{i}}^{\mathrm{t}}<\mathrm{K}_{\mathrm{i}}^{\mathrm{t}} \quad \text { and } \quad \mathrm{R}_{\mathrm{i}}(\cdot)<0 \Rightarrow \mathrm{N}_{\mathrm{i}}^{\mathrm{t}}>\mathrm{K}_{\mathrm{i}}^{\mathrm{t}}
$$

Expression (18) implies that carrying capacity depends on biotic factors including net energies, biomass demands, energy prices and populations. The procedure is to adjust the carrying capacity in period t to be greater than or less than the period t population according to (18). In particular,

$$
K_{i}^{t}=N_{i}^{t} \pm z\left(R_{i}^{t}(\cdot)\right) N_{i}^{t}
$$

where $\mathrm{z}$ is the carrying capacity adjustment as an increasing function of the net energy. In practice, $\mathrm{z}$ will be species dependent and bounded from above. Finally, the new population in period $\mathrm{t}+1$ is obtained using (17) and (19):

$$
\mathrm{N}_{\mathrm{i}}^{\mathrm{t}+1}=\mathrm{N}_{\mathrm{i}}^{\mathrm{t}}+\mathrm{r}_{\mathrm{i}} \mathrm{N}_{\mathrm{i}}^{\mathrm{t}}\left[1-\mathrm{N}_{\mathrm{i}}^{\mathrm{t}} / \mathrm{K}_{\mathrm{i}}^{\mathrm{t}}\right]
$$

Note that the period $t+1$ population is smaller than the period $t$ population if $N_{i}^{t}>K_{i}^{t}$ in $(20)$. 
Unlike other familiar models of predator-prey interactions, the interactions in this model are not based on aggregate differential equations from the so-called Lotka-Volterra model or its many refinements; instead, the interactions are based on the behavior of individual organisms choosing optimum foraging strategies. Basically, rather than the usual approach where one entire population responds to another entire population through differential equations which mask any organism behavior, the population adjustments take place because each species' carrying capacity is a function of the populations and behaviors of the members of all other species. As Anholt (1997) points out: "It seems likely that population dynamics is affected by variation in the behavior of individuals." (p. 633), and the general equilibrium approach employed here demonstrates how this may occur. Organisms optimize given the energy prices, predation risk and their own respiration and maintenance conditions (and abiotic factors which could be incorporated). At the same time, the energy prices are determined in the biomass markets; thus, the populations of all species are taken into account in each predator-prey interaction. The importance of individual behavior is consistent with game formulations of predator-prey systems: “...responses by individual predators or prey may vary as a function of the frequency and form of responses by other predator and prey of the association" (Bouskila, 1998, p. 703), as well as the notion that foraging strategy can be a cause of predator-prey cycles (Abrams, 1992).

\section{Energy Balance}

Kooijman, et al. (1999) indicate that population theories can benefit by making explicit use of mass and energy conservation laws. At an aggregate level in this model, conservation of energy is straightforward. Energy balance requires:

$$
\sum_{i=1}^{m} N_{i} e_{0} x_{i 0}=\sum_{i=1}^{m} N_{i}\left[R_{i}+f^{i}(\cdot)+\beta_{i}+\sum_{j=1}^{i-1} e_{i j} x_{i j}\right]
$$


The left side of (21) is solar energy taken by each representative organism times the population of the organism's species, yielding the total solar energy flowing into the ecosystem. The right side also accounts for the entire populations of each species. The first term in brackets is the total net energy, the second and third terms are the activity and metabolic energy lost to the atmosphere, and the last term is the energy expended in preying, also lost to the atmosphere. Substituting for the $R_{i}$ from (3) and canceling terms yields:

$$
\sum_{i=2}^{m} N_{i} \sum_{j=1}^{i-1} e_{j} x_{i j}=\sum_{i=1}^{m-1} N_{i} \sum_{k=i+1}^{m} e_{i} y_{i k}
$$

If the equilibrium conditions in (13) are satisfied, then (22) must hold: an ecosystem in equilibrium satisfies energy balance. Equilibrium is more stringent than energy balance in the sense that in equilibrium energy demand and energy supply are equal in each market, whereas energy balance only require total demand and total supplies of energy be equal. However, energy balance must hold regardless of whether the ecosystem is in equilibrium. Therefore, a system out of equilibrium exhibits excess demand in some markets and excess supply in other markets, and the excesses must balance.

\section{Numerical Simulations}

A marine ecosystem in Alaska's Aleutian Islands is used to numerically investigate the model. Some detail of this ecosystem is available in Estes and Palmisano (1974) and Estes et al. (1998), only a broad and aggregated picture is used in the simulations. The ecosystem is a food web with four trophic levels illustrated in Figure 2. A kelp forest comprises the primary producers which may include various species of brown and red algae. All primary producer species will be aggregated into a single species called kelp. Similarly, all fish species which utilize the kelp forest are aggregated into a single species called fish. Stellar sea lions (Eumetopias jubatus) and harbor seals (Phoca vitulina) prey on the fish and are combined into one species called pinnepeds. Sea 
urchins (Strongylocentrotus sp.) also prey on the kelp and in turn are preyed upon by sea otters (Enhydra lutris). The killer whale (Orcinus orca) is the top predator and preys on both pinnepeds and otters.

Although the following simulation consists of only six species and the parameters and functional forms are not realistic, the point of the exercise is to explore the operational possibilities and insights offered by the general equilibrium approach. From (3), the net energies of a representative organism of kelp, fish, urchin, pinneped, otter and whale, indexed by 1-6, respectively, are given by (23)-(28), respectively:

$$
\begin{aligned}
& \mathrm{R}_{1}=\left[\mathrm{e}_{0}-\mathrm{e}_{10}\right] \mathrm{x}_{10}-\mathrm{e}_{1} \delta_{12} \mathrm{x}_{10}^{\alpha_{12}}-\mathrm{e}_{1} \delta_{13} \mathrm{x}_{10}^{\alpha_{13}}-\mathrm{r}_{1} \mathrm{x}_{10}^{\gamma_{1}}-\beta_{1} \\
& \mathrm{R}_{2}=\left[\mathrm{e}_{1}-\mathrm{e}_{21}\right] \mathrm{x}_{21}-\mathrm{e}_{2} \delta_{24} \mathrm{x}_{21}^{\alpha_{24}}-\mathrm{r}_{2} \mathrm{x}_{21}^{\gamma_{2}}-\beta_{2} \\
& \mathrm{R}_{3}=\left[\mathrm{e}_{1}-\mathrm{e}_{32}\right] \mathrm{x}_{31}-\mathrm{e}_{3} \delta_{35} \mathrm{x}_{31}^{\alpha_{35}}-\mathrm{r}_{3} \mathrm{x}_{31}^{\gamma_{3}}-\beta_{3} \\
& \mathrm{R}_{4}=\left[\mathrm{e}_{2}-\mathrm{e}_{42}\right] \mathrm{x}_{42}-\mathrm{e}_{4} \delta_{46} \mathrm{x}_{42}^{\alpha_{46}}-\mathrm{r}_{4} \mathrm{x}_{42}^{\gamma_{4}}-\beta_{4} \\
& \mathrm{R}_{5}=\left[\mathrm{e}_{3}-\mathrm{e}_{53}\right] \mathrm{x}_{53}-\mathrm{e}_{5} \delta_{56} \mathrm{x}_{53}^{\alpha}-\mathrm{r}_{5} \mathrm{x}_{53}^{\gamma_{5}}-\beta_{5} \\
& R_{6}=\left[e_{4}-e_{64}\right] x_{64}+\left[e_{5}-e_{65}\right] x_{65}-r_{6 p} x_{64}^{\gamma_{6 p}}-r_{60} x_{65}^{\gamma_{60}}+\left[x_{64}+x_{65}\right]^{\gamma_{6}}-\beta_{6}
\end{aligned}
$$

The terms in (23)- (28) containing $\delta$ and $\alpha$ parameters are the supply functions: $\mathrm{y}_{\mathrm{ik}}=\delta_{\mathrm{ik}} \mathrm{x}_{\mathrm{ij}} \mathrm{ik}_{\mathrm{in}}$ which the ith species is supplying biomass to the kth species, and demanding biomass from the jth species. The terms containing the $\mathrm{r}$ and $\gamma$ parameters are the variable portions of respiration in (3): $\mathrm{f}^{\mathrm{i}}(\cdot)=\mathrm{r}_{\mathrm{i}} \mathrm{x}_{\mathrm{ij}}^{\gamma_{\mathrm{i}}}$. For the whales, variable respiration is divided into three parts which allows for differences in the prices whales must pay in equilibrium for otters and pinnepeds. 
A short-run equilibrium is obtained by solving fourteen equations for fourteen variables: the seven demands $\left(\mathrm{x}_{\mathrm{ij}}\right)$ and the seven prices $\left(\mathrm{e}_{\mathrm{ij}}\right)$. Seven equations are obtained from setting the derivatives of $(23)$ - (28) with respect to the demands equal to zero, and the other seven are the equilibrium conditions:

$$
\begin{array}{lll}
\mathrm{N}_{2} \mathrm{x}_{21}=\mathrm{N}_{1} \delta_{12} \mathrm{x}_{10}^{\alpha_{12}} & (29) & \mathrm{N}_{3} \mathrm{x}_{31}=\mathrm{N}_{1} \delta_{13} \mathrm{x}_{10}^{\alpha_{13}} \\
\mathrm{~N}_{4} \mathrm{x}_{42}=\mathrm{N}_{2} \delta_{24} \mathrm{x}_{21}^{\alpha_{24}} & (31) & \mathrm{N}_{5} \mathrm{x}_{53}=\mathrm{N}_{3} \delta_{35} \mathrm{x}_{31}^{\alpha_{35}} \\
\mathrm{~N}_{6} \mathrm{x}_{64}=\mathrm{N}_{4} \delta_{46} \mathrm{x}_{42}^{\alpha_{46}} & (33) & \mathrm{N}_{6} \mathrm{x}_{65}=\mathrm{N}_{5} \delta_{56} \mathrm{x}_{53}^{\alpha_{56}} \\
& \mathrm{e}_{10}=\mathrm{pN}_{1}^{\mathrm{q}}
\end{array}
$$

Conditions (29)-(34) are from (13), and condition (35) is from Assumption (3) with p and q as parameters.

The procedure for making the long-run population adjustments can be understood by examining any one of the species, say otters. Recall that otter populations will increase (decrease) if net energy is positive (negative). Let $\mathrm{R}_{5}(\cdot)$ be the maximum net energy for otters in short-run equilibrium and set $\mathrm{R}^{\mathrm{a}}=\left|\mathrm{R}_{5}(\cdot)\right|$. Next let

$$
\mathrm{z}^{\mathrm{o}}=\mathrm{b}(2 / \pi) \arctan \mathrm{R}^{\mathrm{a}}
$$

where parameter $b>0$, and $z^{o} \in[0, b)$ will be used to adjust the otter carrying capacity. By (19), period t carrying capacity becomes:

$$
\mathrm{K}_{5}^{\mathrm{t}}=\mathrm{N}_{5}^{\mathrm{t}} \pm \mathrm{z}^{\mathrm{o}} \mathrm{N}_{5}^{\mathrm{t}}
$$

where the plus (minus) obtains if $\mathrm{R}_{5}(\cdot)>(<) 0$. Finally, following $(20)$, the new population in period $t+1$ is determined by (38).

$$
\mathrm{N}_{5}^{\mathrm{t}+1}=\mathrm{N}_{5}^{\mathrm{t}}+\mathrm{r}_{5} \mathrm{~N}_{5}^{\mathrm{t}}\left[1-\mathrm{N}_{5}^{\mathrm{t}} / \mathrm{K}_{5}^{\mathrm{t}}\right]
$$


There is insufficient data for the Aleutian ecosystem, or any other ecosystem that I know of, to assign values to all parameter with confidence. However, bounds on parameters can be set: 1) from observations about the relationships between population densities and predation, 2) based on necessary and sufficient conditions for a maximum to the net energy problem, and 3) using estimates of ecological efficiencies. Some exploration of setting bounds is in the Appendix. In practice, parameters within the bounds can be obtained through statistical estimation applied to sample data from well defined populations. For example, to estimate a supply function for an organism, data would include calories of energy and grams of biomass exchanged between predator and prey under varying climactic conditions and abiotic surroundings. Estimates of the $\alpha$ and $\delta$ supply parameters can be obtained using regression techniques applied to alternative supply functional forms, and the estimates would be examined for their statistical significance. In the simulations, parameter values were chosen so that the computed ecological efficiencies were within an order of magnitude of efficiencies observe in field work. Values of all parameters in the simulations are shown in Table 1.

\section{Results}

Table 2 reports populations, demands, prices and net energies for the first five short-run equilibriums. For example, in column four, row two, the initial sea urchin population is 48000 , and given all parameter values and initial populations of the other five species, the representative urchin demands 71.4 kelp biomass units for which it pays an energy price of 96.4 per unit. This yields the urchin - 0.2 net energy after respiration. Moving down the column, because its net energy is negative the urchin population decreases, and based on the adjustment equations the period two population is 47482 . The other species populations adjust as well according to their net energies, and for the urchin the new demand and energy price in period two are 73.7 and 93.3, respectively. 
Because demand increased and price decreased the new net energy is greater in period two at 228.5. The positive implies an increase in population in period three to 50762.

Consider the predator/prey dynamics of the otter/urchin interaction illustrated in Table 2. Between periods two and three both populations increase. The increase in urchins makes preying on them less costly to the otter, but the increase in otters makes preying on urchins more costly owing to competition among otters. The net result is a slight increase in the price of capturing urchins (8.94 to 8.96) and a slight decrease in otter demand (586 to 578). Between periods three and four the population of urchins goes down and the population of otters goes up. Both population changes work to make urchins more difficult to capture, and the price of capturing urchins increases by a greater margin this time (8.96 to 9.07 ), while otter demand decreases substantially (578 to 513). Between periods four and five the population of urchins goes up and the population of otters goes down. Both changes reinforce each other again, but in the opposite direction of the previous period's changes, and the price of capturing urchins decreases (9.07 to 8.93), while otter demand increases (513 to 595).

In Figure 3, the whale demands for otters and pinnepeds and the associated prices are shown for twenty periods; however, the energy prices were rescaled to make easy visual comparison with demands so only their relative and not absolute values are meaningful. The biomass demands for the first five periods in Figure 3 are from Table 2. The Figure clearly illustrates that the whales are obeying the "law of demand"; at higher (lower) prices the whales demand less (more) biomass. In addition, the whale demand for pinnepeds is almost three times its demand for otters. This follows because the embodied energy in a unit of pinneped biomass, $\mathrm{e}_{4}$, is assigned a value that exceeds the embodied energy in a unit of otter biomass, $e_{5}$, by a factor of ten, and $\delta_{46}>\delta_{56}$ which means pinnepeds are more rewarding prey. (See Table 1.) To reiterate, while these parameters may not be realistic, their relative values lead to expected predator behavior. 
As expected, whales also substitute between their two prey species as relative energy prices change. To show this, return to equation (9) and note that because whales are the top predator they do not supply biomass to other species and the partial derivatives of the supply functions ( $\partial \mathrm{y} / \partial \mathrm{x})$ are zero. Substitute from Table 1 and from period two in Table 2 into the remaining terms of equation 9 to obtain 3.26 for both sides. This simply demonstrates that whales are behaving as if they are maximizing net energy. Now consider how prices and demands change from period two to period three. The ratio of net energy gains on the left side of (9) decreases from 3.26 to 2.85 , because the energy price whales paid for otters decreased (0.033 to 0.020$)$ relatively more than the energy price whales paid for pinnepeds ( 0.780 to 0.772$)$. The relatively less expensive otters caused whales to substitute otters for pinnepeds which can be seen in the changed pinneped/otter biomass ratio $\left(\mathrm{x}_{64} / \mathrm{x}_{65}\right)$ which went from 3.08 to 2.73 between the two periods.

Figure 4 shows the populations for all six species over twenty periods. The populations have been rescaled to fit on the same graph, so again only the relative values are meaningful. From its initial population of 5 million, kelp slowly increased and leveled off at about 5.4 million. The increased kelp population led to greater energy available to the food web, although most of the increase was accounted for by kelp. That is, in the first (twentieth) period the total incoming energy was $\mathrm{N}_{1} \mathrm{e}_{0} \mathrm{X}_{10}=3275 \times 10^{6}\left(3524 \times 10^{6}\right)$. The increase of $249 \times 10^{6}$ was allocated as follows: $41 \%$ went to increased variable respiration for the larger kelp population; $21 \%$ went to increased fixed respiration of the larger kelp population; 3\% went to greater expenditure of kelp in obtaining solar energy; and the remaining 35\% went to fluctuations in net energies and energy expenditures on preying and respiration for the remaining five species.

The fish and pinneped populations and the urchin and otter populations in Figure 4 conform to familiar predator-prey interactions with the peaks and valleys of the predator species lagging the peaks and valleys of the prey species. Running the model over more time periods repeats the same 
patterns of fluctuating populations. Thus, none of the species achieve zero net energy and a stable population in this example, and long-run equilibrium is not attained. Because the populations are sensitive to the starting population values, long-run equilibrium will be as well. The population patterns do exhibit neutral stability as discussed by Pielou (1977).

Finally, the fluctuations in the whale population in Figure 4 follow the fluctuations in the pinneped and otter populations in a less discernable manner, because the whales can switch between their prey species. Not surprisingly, because the whales feed much more heavily on pinnepeds than otters, the whale fluctuations conform more closely to the pinneped fluctuations.

\section{Integration with Economic Models}

Integrating the general equilibrium ecosystem model developed here with extant economic models entails identifying key variables that influence both systems and determining where to incorporate them. Humans interact with ecosystems in myriad ways that can be addressed by augmenting (3), the net energy expression. Perhaps the most important human influence is habitat modification or eradication through land use practices. Using $\mathrm{e}_{\mathrm{i} 0} \mathrm{x}_{\mathrm{i} 0}$, the incoming solar energy to organisms in species $\mathrm{i}$, the amount of solar energy taken by primary producers will depend on how much land is available for habitat. The $\mathrm{x}_{\mathrm{i} 0}$ can be made a function of the available hectares for primary producers after land development. The effects of increased land development can then be traced through the ecosystem, most likely leading to a downsized ecosystem, although some species will be impacted more than others and the model can identify these differential impacts.

Besides primary producers, species are impacted through habitat modification when abiotic factors are altered. Acid deposition from human activities that reduce soil $\mathrm{pH}$, or the mounting evidence of human induced climate change, or timber harvests that reduce nesting sites are examples. To the extent that these activities ultimately reduce the net energy of an organism 
through added stress, their influence may be captured by having humans directly crop net energy in a manner similar to Hannon (1976).

Another interaction is direct human control of species populations. Humans cull species through fishing, hunting and "pest" control while at the same time increase populations of species through stocking and reintroductions. In the model, these human activities can be introduced by harvesting (or adding to) the adjustments to $\mathrm{N}_{\mathrm{i}}$ in equation (20).

Agriculture impacts ecosystems through land development, pesticide use and runoff, supplying crops to pollinator species, etc. Pesticides may change the functional form of $\mathrm{f}^{\mathrm{i}}(\bullet)$ if the organism's physiological processes are affected, and pollinating species may be provided with alternative species to "prey" on with the introduction of crops.

Species populations, the $\mathrm{N}_{\mathrm{i}}$, are the most likely candidates for ecosystem variables that can be included in the economic models. Populations of harvested species will have direct influence on the economic benefits associated with these activities. Falling populations of pollinator species will impact agricultural production functions and decrease agricultural output. Habitat modification that reduces wetland biodiversity may diminish water quality and require increased tax revenues and government expenditures for water purification. In turn, the economy will respond to changes in agricultural output or diminished water quality in ways that further change species populations. For example, if farmers' revenue losses from decreased crop output yield negative profits, they may sell their land to developers.

In the end, whether integrating a general equilibrium ecosystem model with an economic model is useful will depend both on the accuracy of the predictions of the ecosystem model in isolation, and on how well variables from one model can be effectively incorporated in the other. With respect to accuracy, estimating functional forms for the energy losses and supplies in (3) is primary, and this will require data collection and perhaps new field techniques that ultimately might 
prove very costly. Nevertheless, the obvious interconnectedness of economies and ecosystems and the increasing mutual stresses the systems are experiencing call for opening inquiries into new methods of integration. 


\section{Appendix}

As stated in the text, bounds on parameter values for the supply and respiration functions can be found: 1) from observations about the relationships between population densities and predation, 2) based on necessary and sufficient conditions for a maximum to the net energy problem, and 3) using estimates of ecological efficiencies. For 1), and using the functional forms from the Aleutian food web (noting that other functional forms can be applied as well), three of the equilibrium conditions are given by (29), (31) and (33). Using (10), rewrite them as:

$$
\begin{array}{r}
\mathrm{F}^{1}\left(\mathrm{e}_{21}, \mathrm{e}_{10}\right)=\mathrm{N}_{2} \mathrm{x}_{21}\left(\mathrm{e}_{21}\right)-\mathrm{N}_{1} \delta_{12} \mathrm{x}_{10}^{\alpha_{12}}\left(\mathrm{e}_{10}\right)=0 \\
\mathrm{~F}^{2}\left(\mathrm{e}_{42}, \mathrm{e}_{21}\right)=\mathrm{N}_{4} \mathrm{x}_{42}\left(\mathrm{e}_{42}\right)-\mathrm{N}_{2} \delta_{24} \mathrm{x}_{21}^{\alpha_{24}}\left(\mathrm{e}_{21}\right)=0 \\
\mathrm{~F}^{3}\left(\mathrm{e}_{64}, \mathrm{e}_{42}\right)=\mathrm{N}_{6} \mathrm{x}_{64}\left(\mathrm{e}_{64}, \mathrm{e}_{65}\right)-\mathrm{N}_{4} \delta_{46} \mathrm{x}_{42}^{\alpha_{46}}\left(\mathrm{e}_{42}\right)=0
\end{array}
$$

The exercise is to determine how the energy prices ( $\left(\mathrm{e}_{\mathrm{ij}}\right.$ 's) change with changes in populations (N's). From the implicit function theorem, we obtain:

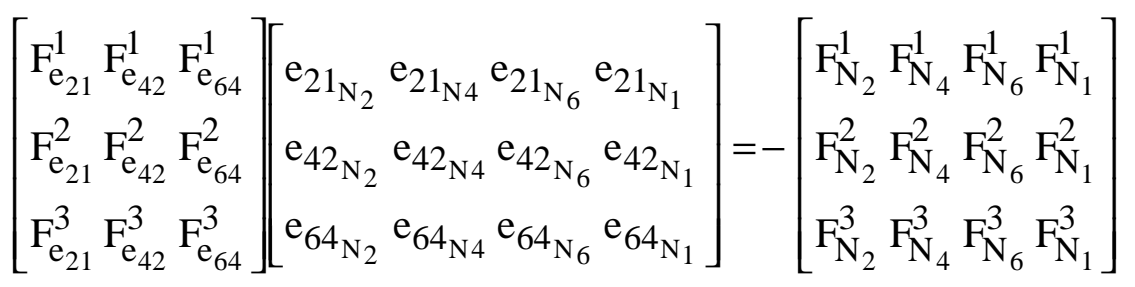

where subscripts are partial derivatives. The second matrix on the left side of (A.1), denoted $\mathbf{e}_{\mathbf{N}}$, is the matrix of the price changes. Substituting the partials from (29'), (31') and (33') into (A.1) yields:

$\left[\begin{array}{ccc}\mathrm{N}_{2} \frac{\partial \mathrm{x}_{21}}{\partial \mathrm{e}_{21}} & 0 & 0 \\ -\mathrm{a}_{24} \mathrm{~N}_{2} \mathrm{~d}_{24} \mathrm{x}_{21}^{\mathrm{a}_{24}-1} \frac{\partial \mathrm{x}_{21}}{\partial \mathrm{e}_{21}} & \mathrm{~N}_{4} \frac{\partial \mathrm{x}_{42}}{\partial \mathrm{e}_{42}} & 0 \\ 0 & -\mathrm{a}_{46} \mathrm{~N}_{4} \mathrm{~d}_{46} \mathrm{x}_{42}^{\mathrm{a}_{46}-1} \frac{\partial \mathrm{x}_{42}}{\partial \mathrm{e}_{42}} & \mathrm{~N}_{6} \frac{\partial \mathrm{x}_{64}}{\partial \mathrm{e} 64}\end{array}\right] \mathrm{e}_{\mathrm{N}}=\left[\begin{array}{rrcc}-\mathrm{x}_{21} & 0 & 0 & \mathrm{~d}_{12} \mathrm{x}_{10} \\ \mathrm{~d}_{24} \mathrm{x}_{21} & -\mathrm{x}_{42} & 0 & 0 \\ 0 & \mathrm{~d}_{46} \mathrm{x}_{42} & -\mathrm{x}_{46} & 0\end{array}\right]$ 
The determinant of the left-most matrix is $\left|\mathrm{F}_{\mathrm{e}}^{\mathrm{i}}\right|=\mathrm{N}_{2} \mathrm{~N}_{4} \mathrm{~N}_{6} \frac{\partial \mathrm{x}_{21}}{\partial \mathrm{e}_{21}} \frac{\partial \mathrm{x}_{42}}{\partial \mathrm{e}_{42}} \frac{\partial \mathrm{x}_{64}}{\partial \mathrm{e}_{64}}<0$ from (12). Then using Cramer's Rule to solve for the partials of the $\mathrm{e}_{\mathrm{ij}}$ gives us

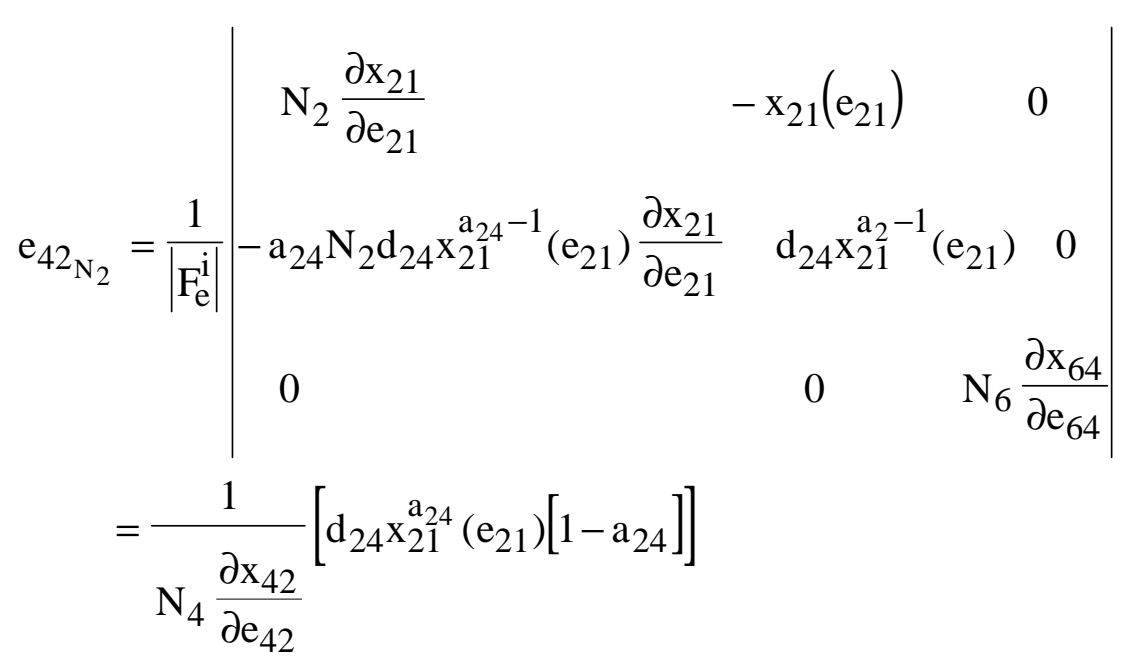

Assuming an increase (decrease) in the population of fish makes it easier for pinnepeds to prey on fish and, therefore, lowers (raises) the price pinnepeds pay for fish, $\mathrm{e}_{42_{\mathrm{N}_{2}}}$ will be negative. This places bounds on $\mathrm{a}_{24}$ : from (A.3) and (12) we have $0<\mathrm{a}_{24}<1$.

Continuing to use Cramer's rule, the reader can verify that $\mathrm{e}_{42_{\mathrm{N}_{1}}}<0, \mathrm{e}_{42_{\mathrm{N} 4}}>0$, and $\mathrm{e}_{42_{\mathrm{N} 6}}=$ 0 , indicating that an increase in the kelp population and a decrease in the pinneped population will both decrease the price pinnepeds must pay for fish, while a change in the whale population has no effect on the price paid by pinnepeds for fish. No further information on parameter bounds are forthcoming from these last results.

Second-order conditions for a maximum also can be used to set parameter bounds. For example, consider the net energy function for fish, (24). The second-order sufficient condition for a maximum requires that the second derivative of (24) with respect to $x_{21}$ be negative; i.e.,

$$
\frac{\partial^{2} \mathrm{R}}{\partial \mathrm{x}_{21}^{2}}=\mathrm{e}_{2} \delta_{24} \alpha_{24} \mathrm{x}_{21}^{\alpha_{24}-2}\left[1-\alpha_{24}\right]+\mathrm{r}_{2} \gamma_{2}\left[1-\gamma_{2}\right] \mathrm{x}_{21}^{\gamma_{2}-2} \prec 0
$$


From (A.3) $\alpha_{24}<1$, therefore, it must be that $\gamma_{2}>1$ to ensure a maximum.

Finally, if estimates of ecological efficiencies are available, they can shed light on the reasonableness of parameter values. There are a variety of efficiencies defined in the literature; employing a simple definition from Pimm (1982) consider the energy taken in one trophic level divided by the energy taken in the adjoining trophic level. Referring to period 5 in Table 2, the ecological efficiency between the trophic level comprised of urchins and fish and the trophic level comprised of kelp is:

$$
\begin{gathered}
{\left[\left(\mathrm{e}_{1}-\mathrm{e}_{21}\right) \mathrm{x}_{21} \mathrm{~N}_{1}+\left(\mathrm{e}_{1}-\mathrm{e}_{31}\right) \mathrm{x}_{31} \mathrm{~N}_{3}\right] /\left(\mathrm{e}_{0}-\mathrm{e}_{10}\right) \mathrm{x}_{10} \mathrm{~N}_{1}=} \\
{[(200-116.7)(65.26)(46308)+(200-89.3)(76.6)(47343)] /(500-11.99)(1.306)(5289450) \approx 19 \% .}
\end{gathered}
$$




\section{References}

Abrams, P.A. (1992). Adaptive foraging by predators as a cause of predator-prey cycles. Evolutionary Ecology, 6, 56-72.

Anholt, B.R. (1997). How should we test for the role of behavior in population dynamics? Evolutionary Ecology, 11, 633-640.

Arrow, K. (1968) Economic equilibrium. International Encyclopedia of the Social Sciences 4, New York: Mcmillan Company.

Arrow, K., Bolin, B.,Costanza, R., Dasgupta, P., Folke, C., Holling, C.S., Jansson, B., Levin, S., Maeler, K., Perrings, C. \& Pimentel, D. (1995) Economic growth, carrying capacity and the environment. Science, 268, April, 520-21.

Bartell, S.N. (1982). Influence of prey abundance on size-selective predation by bluegills. Transactions of the American Fisheries Association, 111, 453-461.

Bascompte, J. \& Sole, R.V. (1998) Effects of habitat destruction in a prey-predator metapopulation model. Journal of Theoretical Biology 195, 383-393.

Beissinger, S.R. \& Perrine, J. (forthcoming, 2000) Extinction, recovery and the endangered species act. Protecting Endangered Species in the U.S.: Biological Needs, Political Realities and Economic Choices, eds. J. Shogren \& J. Tschirhart. New York: Cambridge University Press.

Bossel, H. (1987). Viability and sustainability: Matching development goals to resource constraints. Futures 19, 114-128.

Bouskila, A., Robinson, M.E., Roitberg, B.D. \& Tenhumberg, B. (1998) Life-history decisions under predation risk: importance of a game perspective. Evolutionary Ecology 12, 701-715.

Chazdon, R.L. \& Pearcy, R.W. (1986) Photosynthetic responses to light variation in rainforest species. Oecologica. 69, 524-31.

Crocker, T.D. \& Tschirhart, J. (1992) Ecosystems, externalities and economies. Environmental and Resource Economics, 2, 551-567.

Daily, G.C. (1997). What are ecosystem services? In Nature's Services, ed. G.C. Daily, Washington, D.C.: Island Press.

Derrickson, S.R. \& Snyder, N.F.R. (1992). Potentials and limitations of captive breeding in parrot conservation. In S.R. Beissinger \& N.F.R. Snyder, eds. New World Parrots in Crisis: Solutions from Conservation Biology. Washington, D.C.: Smithsonian Institution Press.

Estes, J.A. \& Palmisano, J.F. (1974). Sea otters: their role in structuring nearshore communities. Science 185, 1058-60. 
Estes, J.A., Tinker, M.T., Williams, T.M., \& Doak, D.F. (1998). Killer whale predation on sea otters linking oceanic and nearshore ecosystems. Science 282, 473-6.

Ginsburgh, V. \& Keyzer, M. (1997) The Structure of Applied General Equilibrium Models. Cambridge, Mass.: MIT Press.

Gutierrez, A.P. (1996). Applied Population Ecology: A Supply-Demand Approach. New York: John Wiley \& Sons, Inc.

Hannon, B. (1973). The structure of ecosystems. Journal of Theoretical Biology 41, 535-546.

Hannon, B. (1976). Marginal product pricing in the ecosystem. Journal of Theoretical Biology 56, 253-267.

Hannon, B. (1979). Total energy cost in ecosystems. Journal of Theoretical Biology 80, 271-93.

Hannon, B., Costanza, R. \& Ulanowicz, R. (1991). A general accounting framework for ecological systems: a functional taxonomy for connectivist ecology. Theoretical Population Biology 40, 78104.

Herendeen, R. (1991). Do economic-like principles predict ecosystem behavior under changing resource constraints? In Theoretical Studies Ecosystems: The Network Perspective, eds. T. Burns and M. Higashi, 261-87, New York: Cambridge University Press.

Jablonski, D. (1991). Science 235, 754.

Jorgensen, S.E. (1982). Exergy and buffering capacity in ecological systems. In Energetics and Systems, ed. W. Mitsch, Ragade, R., Bosserman, R. \& Dillon, J. 61-72, Ann Arbor: Ann Arbor Science.

Jorgensen, S.E. (1986). Structural dynamic model. Ecological Modeling 31, 1-9.

Kooijman, S.A.L.M., Kooi, B.W. \& Hallam, T.G. (1999) The application of mass and energy conservation laws in physiologically structured population models of heterotrophic organisms. Journal of Theoretical Biology 197, 371-392.

Krugman, P. (1998) Rationales for rationality. Rationality in Economics: Alternative Perspectives. ed. Ken Dennis, Boston: Kluwer Academic Press.

Landa, J.T. (1999) Bioeconomics of some nonhuman and human societies: new institutional economic approach. Journal of Bioeconomics 1, 5-12.

Landa, J.T. \& Ghiselin, M.T. (1999) The emerging discipline of bioeconomics: aims and scope of the Journal of Bioeconomics, Journal of Bioeconomics 1, 5-12.

Leader-Williams, N. (1990). Black rhinos and African elephants: lessons for conservation funding. Oryx. 24, 23-29. 
Lima, S.L. \& Dik, L.M. (1990) Behavioral decisions made under the risk of predation: a review and prospectus. Canadian Journal of Zoology 68, 619-640.

Lotka, A.J. (1922) Contribution to the energetics of evolution. Proceedings of the National Academy of Science U.S.A. 8, 147-55.

May, R., Lawton, J.H. \& Stork, N.E. (1995) Extinction Rates. Oxford: Oxford University Press.

Menge, B. (1972) Foraging strategy of a starfish in relation to actual prey availability and environmental predictability. Ecological Monographs 42, 25-50.

Odum, H.T. (1988) Self-organization, transformity and information. Science 242, 1132-1139.

Perrings, C. (1986) Conservation of mass and instability in a dynamic economy-environment system. Journal of Environmental Economics and Management 3, 199-211.

Pielou, E.C. (1977) Mathematical Ecology. New York: John Wiley \& Sons.

Pimm, S., Russell, G., Gittleman, J. \& Brooks, T. (1995). Science 269, 347-350.

Pimm, S.L. (1982) Food Webs New York: Chapman and Hall.

Shoven, J.B. \& Whalley, J. (1984). Applied general equilibrium models of taxation and international trade: an introduction and survey. The Journal of Economic Literature XXII, 3, 10071051.

Snyder, N.F.R., Derrickson, S., Beissinger, S.R., Wiley, J.W., Smith, T.B., Toone, W.D. \& Miller, B. (1996). Limitations of captive breeding in endangered species recovery. Conservation Biology 10, 338-348.

Tilman, D., Knops, J., Wedin, D., Reich, P., Ritchie, M. \& Siemann, E. (August 1997). The influence of functional diversity and composition on ecosystem processes. Science 277, 29, 13001302.

Tirole, J. (1989). The Theory of Industrial Organization. Cambridge, MA: The MIT Press.

Tschirhart, J. \& Crocker, T. (1987). Economic valuation of ecosystems. Transactions of the American Fisheries Society 116, 469-478.

Tullock, G. (1999) Some personal reflections on the history of bieconomics. Journal of Bioeconomics 1, 13-18.

Ulanowicz, R.E. (1980) An hypothesis on the development of natural communities. Ecological Modeling 85, 223-45.

Ulanowicz, R.E. (1991). Contributory values of ecosystem resources. in R. Costanza: Ecological Economics: The Science and Management of Sustainability. New York: Columbia University Press. 
Varian, H. (1992). Microeconomic Analysis. $3^{\text {rd }}$ ed. New York: W.W. Norton and Co.

Werner, E. E., \& Hall, D.J. (1974). Optimal foraging and the size selection of prey by bluegill sunfish. Ecology 55, 1042-1052. 
Table 1 - Simulation Parameters

\begin{tabular}{|c|c|c|c|c|c|c|c|}
\hline & kelp & fish & urchins & pinnepeds & otters & \multicolumn{2}{|c|}{$\begin{array}{l}\text { whales } \\
\text { epeds }\end{array}$} \\
\hline $\begin{array}{c}\text { Embodied } \\
\text { Energy }\end{array}$ & $\begin{array}{l}e_{0}=500 \\
e_{1}=200\end{array}$ & $\mathrm{e}_{2}=10$ & $e_{3}=10$ & $\mathrm{e}_{4}=1$ & $\mathrm{e}_{5}=0.1$ & & \\
\hline Supplies & $\begin{array}{c}p=q=.25 \\
\delta_{12}=.5 \delta_{13}=.6 \\
\alpha_{12}=\alpha_{13}=.5\end{array}$ & $\begin{array}{c}\delta_{24}=8 \\
\alpha_{24}=.5\end{array}$ & $\begin{array}{c}\delta_{35}=6 \\
\alpha_{35}=.5\end{array}$ & $\begin{array}{c}\delta_{46}=4 \\
\alpha_{46}=.5\end{array}$ & $\begin{array}{c}\delta_{56}=1.5 \\
\alpha_{56}=.5\end{array}$ & & \\
\hline $\begin{array}{l}\text { Variable } \\
\text { Respir. }\end{array}$ & $\begin{array}{c}\mathrm{r}_{1}=150 \\
\gamma_{1}=2\end{array}$ & $\begin{array}{c}r_{2}=0.6 \\
\gamma_{2}=2\end{array}$ & $\begin{array}{c}r_{3}=0.7 \\
\gamma_{3}=2\end{array}$ & $\begin{array}{c}\mathrm{r}_{4}=0.001 \\
\gamma_{4}=2\end{array}$ & $\begin{array}{c}r_{5}= \\
0.0009 \\
\gamma_{5}=2\end{array}$ & $\begin{array}{c}r_{6 p}= \\
0.00002 \\
\gamma_{6}=.5 \\
\gamma_{6 p}=2\end{array}$ & $\begin{array}{c}r_{60}= \\
0.00002 \\
\gamma_{60}=2\end{array}$ \\
\hline $\begin{array}{c}\text { Fixed } \\
\text { Respir. }\end{array}$ & $\beta_{1}=130$ & $\begin{array}{l}\beta_{2}= \\
2100\end{array}$ & $\begin{array}{l}\beta_{3}= \\
3319\end{array}$ & $\beta_{4}=355$ & $\beta_{5}=264$ & $\beta_{6}=$ & \\
\hline $\begin{array}{c}\text { Growth } \\
\text { Rates (b) }\end{array}$ & 0.3 & 0.3 & 0.3 & 0.3 & 0.3 & 0 & \\
\hline
\end{tabular}


Table 2 - Food Web Simulation

\begin{tabular}{|c|c|c|c|c|c|c|c|}
\hline period 1 & kelp & fish & urchins & pinnepeds & otters & \multicolumn{2}{|c|}{ whales } \\
pinnepeds & otters \\
\hline Populations & 5000000 & 45000 & 48000 & 4500 & 4500 & \multicolumn{2}{|c|}{80} \\
\hline Demands (xij) & 1.31 & 63.5 & 71.4 & 638 & 541 & 5681 & 1962 \\
\hline Prices (eij) & 11.82 & 118.8 & 96.4 & 8.65 & 9.02 & 0.778481 & 0.0272233 \\
\hline Net Energies & 0.30 & 0.6 & -0.2 & 0.9 & -2.4 & \multicolumn{2}{|c|}{1.2} \\
\hline
\end{tabular}

\begin{tabular}{|c|c|c|c|c|c|c|c|}
\hline period 2 & kelp & fish & urchins & pinnepeds & otters & \multicolumn{2}{|c|}{ whales } \\
pinnepeds & otters \\
\hline Populations & 5105020 & 46324 & 47482 & 4639 & 4174 & \multicolumn{2}{|c|}{82.9} \\
\hline Demands (xij) & 1.31 & 63.0 & 73.7 & 634 & 586 & 5638 & 1829 \\
\hline Prices (eij) & 11.88 & 119.4 & 93.3 & 8.65 & 8.94 & 0.780268 & 0.0326184 \\
\hline Net Energies & 0.22 & -37.9 & 228.5 & -3.4 & 43.3 & \multicolumn{2}{|c|}{-19.1} \\
\hline
\end{tabular}

\begin{tabular}{|c|c|c|c|c|c|c|c|}
\hline period 3 & kelp & fish & urchins & pinnepeds & otters & \multicolumn{2}{|c|}{ whales } \\
& & & & & & 4412 & \multicolumn{2}{|c|}{74.4} \\
\hline populations & 5185490 & 40510 & 50762 & 4262 & 6738 \\
\hline Demands (xij) & 1.31 & 73.1 & 70.0 & 650 & 578 & 5843 & 2138 \\
\hline Prices (eij) & 11.93 & 107.6 & 98.4 & 8.62 & 8.96 & 0.77188 & 0.200716 \\
\hline Net Energies & 0.16 & 767.9 & -135.6 & 17.0 & 34.6 & \multicolumn{2}{|c|}{53.9} \\
\hline
\end{tabular}

\begin{tabular}{|c|c|c|c|c|c|c|c|}
\hline period 4 & kelp & fish & urchins & pinnepeds & otters & $\begin{array}{r}\text { wh } \\
\text { pinnepeds }\end{array}$ & otters \\
\hline Populations & 5245520 & 43313 & 44279 & 4500 & 4663 & \multicolumn{2}{|c|}{78.7} \\
\hline Demands (xij) & 1.31 & 69.2 & 81.2 & 641 & 513 & 5792 & 2015 \\
\hline Prices (eij) & 11.96 & 112.1 & 83.0 & 8.64 & 9.07 & 0.773978 & 0.0250521 \\
\hline Net Energies & 0.11 & 440.4 & 1029.1 & 4.61 & -28.4 & \multicolumn{2}{|c|}{31.3} \\
\hline
\end{tabular}

\begin{tabular}{|c|c|c|c|c|c|c|c|}
\hline period 5 & kelp & fish & urchins & pinnepeds & otters & \multicolumn{2}{|c|}{ whales } \\
pinnepeds & otters \\
\hline Populations & 5289450 & 46308 & 47343 & 4732 & 4180 & \multicolumn{2}{|c|}{83.1} \\
\hline Demands (xij) & 1.31 & 65.3 & 76.6 & 633 & 595 & 5727 & 1840 \\
\hline Prices (eij) & 11.99 & 116.7 & 89.3 & 8.66 & 8.93 & 0.776683 & 0.0321674 \\
\hline Net Energies & 0.08 & 132.4 & 526.1 & -5.28 & 52.6 & \multicolumn{2}{|c|}{2.06} \\
\hline
\end{tabular}




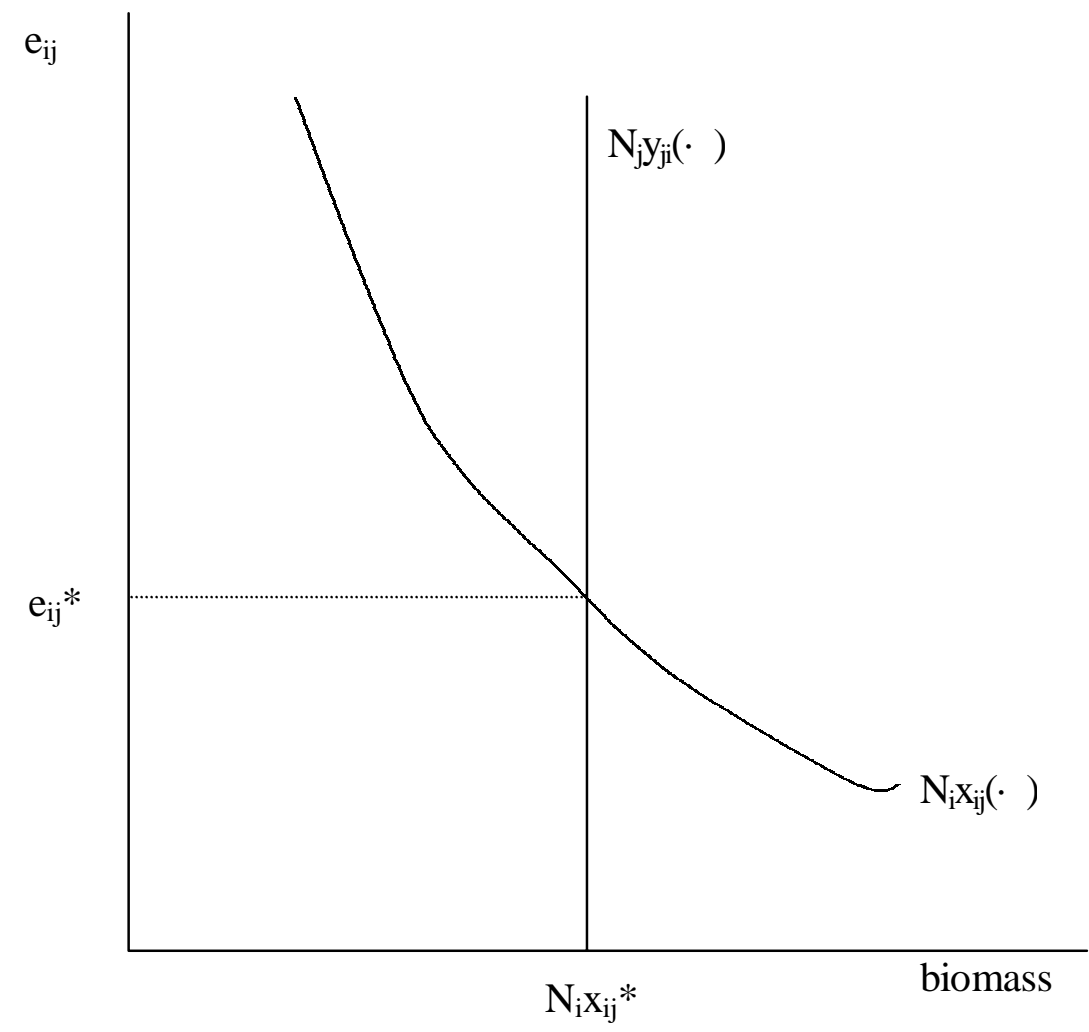

Figure 1

Demand and Supply in a Market 


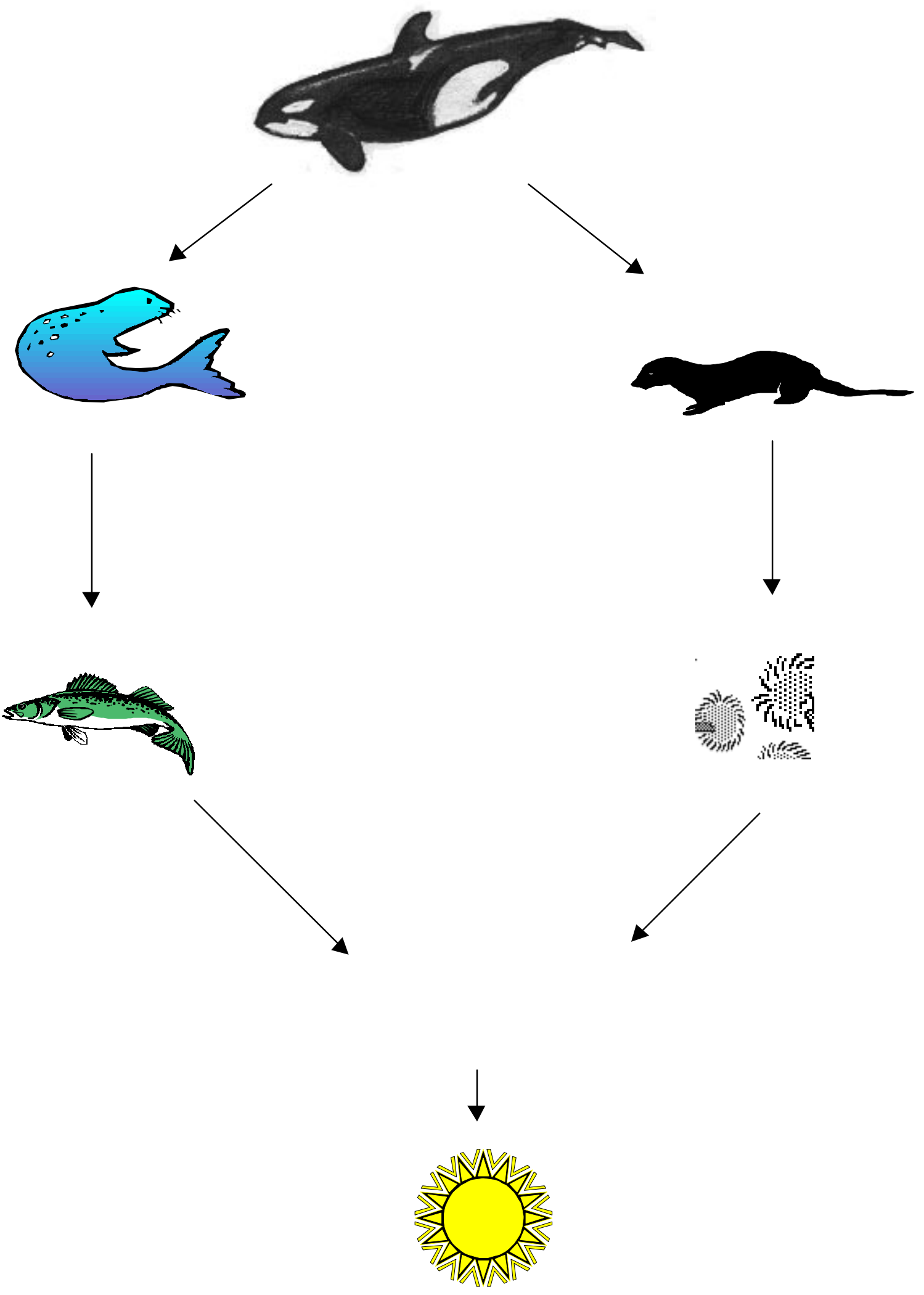

Figure 2

Food Web 
Figure 3 - Whale Demands

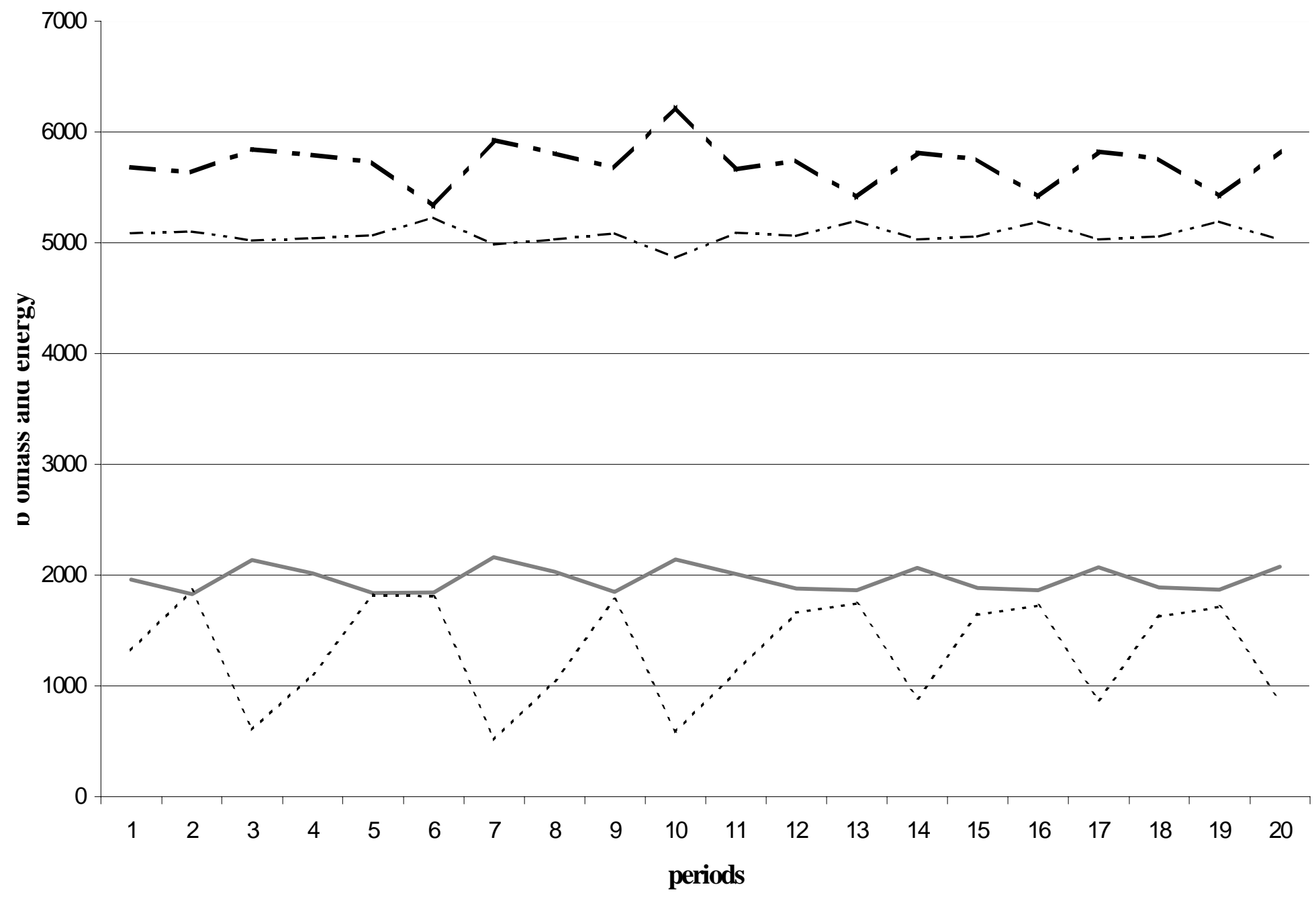

- - pinnepeds —otters - . - - pinneped price - . - . otter price 
Figure 4 - Populations

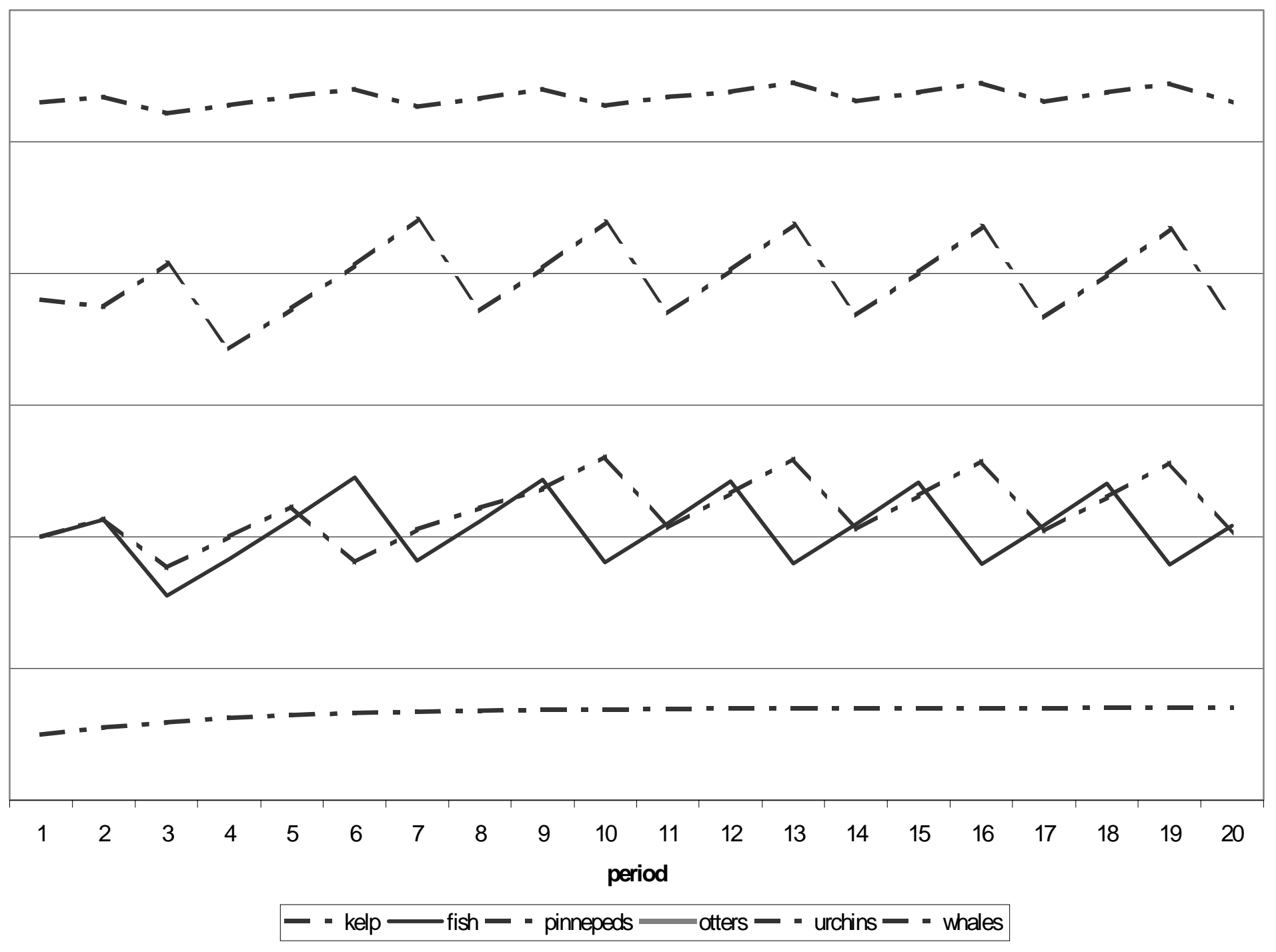




\section{Endnotes}

${ }^{i}$ Odum (1988) has stressed the need for integrating ecological functions into economic theory.

ii There are ecologists and environmentalists who take exception to quantifying monetarily the value of natural resources, because this may lead to trading these resources for material goods to the detriment of the environment. This is a legitimate concern; however, any integration of ecology and economics will inevitably lead to identifying opportunity costs of alternative policies which is tantamount to valuing natural resources in terms of alternative opportunities, if not monetarily.

iii Including cyclic flows would be an extension of this model. In economics, materials flow circularly so altering the ecosystem model to account for circular flows would be relatively straightforward.

${ }^{\mathrm{iv}}$ I am grateful to a referee for pointing out that either exergy or ascendancy incorporate elements of the second law of thermodynamics, and, therefore, are more likely to perform better than net energy incorporating the first law. Second law considerations may be more analytically difficult, but are a promising avenue for future research.

${ }^{v}$ Optimizing behavior or rational decision making is the fundamental postulate in microeconomic theory. The possibility that economic agents may not optimize has received attention, but has not been employed widely in analyses. And behavior that might appear nonoptimizing is sometimes dismissed as optimizing behavior under time or information constraints (Tirole, 1989). Krugman (1998) points out that economists do not truly believe that people are perfectly rational decision makers, yet economists continue to employ rationality as an analytical tool because of its explanatory power, often yielding predictions at odds with but more accurate than popular opinion. Tullock (1999) goes as far as to claim that in biology and economics "the basic problem (is) maximizing subject to constraints." (p. 15) Alternatively, Landa and Ghiselen (1999) state that rational behavior "may be one tunnel vision that afflicts economics" (p. 7) and other biologists question the optimizing notion (E.g., Bossel, 1987). Nevertheless, Landa and Ghiselen also point out that biologists do take into account some rational behavior.

${ }^{v i}$ For examples of substitution behavior in the field, see Menge (1972), Werner and Hall (1974) or Bartell (1982).

vii Input/output type models that provide an accounting framework for ecosystem energy, nutrient and other flows would be useful in generating the data required for the model used here. For a general accounting ecosystem model see Hannon, Costanza and Ulanowicz (1991).

viii Ulanowicz (1991) employs an interesting general equilibrium ecosystem model to determine the value of various species based on their importance, or contribution, to other species. He does not employ optimizing behavior.

${ }^{\text {ix }}$ Nobel Laureate Kenneth Arrow (1968) states: "Whatever the source of the (economic equilibrium) concept, the notion that through the workings of an entire system effects may be very different from, and even opposed to, intentions is surely the most important intellectual contribution that economic thought has made to the general understanding of social processes." (p. 376)

${ }^{\mathrm{x}}$ If defending territory or other forms of intra-species competition are significant for a species, then the population of the species, which is introduced below, could be included in the respiration function.

${ }^{x i}$ For example, if the species population consisted of 100 deer mice and 5 were captured by predators, then the biomass supplied from each representative 'average' mouse would be 0.05 .

${ }^{x i i}$ Second-order sufficient conditions imply that the sum of the $y_{\mathrm{ik}}$ and $\mathrm{f}^{\mathrm{i}}$ functions is strictly convex. In the simulations parameters are chosen to ensure strict convexity. (See, e.g., Varian, 1992.) Strict convexity implies that the sum of the energy lost to predation risk and respiration increases at an increasing rate with demand.

xiii Details on the comparative statics is available from the author on request.

${ }^{\text {xiv }}$ In economic models the short run refers to a fixed number of firms, while in the long run the number of firms adjusts to drive profits to zero. 
${ }^{\mathrm{xv}}$ If the demands from the organism's maximization problem are substituted into (3), the result is a net energy function which will be labeled $\mathrm{R}_{\mathrm{i}}^{*}\left(\mathbf{e}_{\mathrm{i}}\right)$. Thus, while $\mathrm{R}_{\mathrm{i}}$ is an expression that gives the net energy for any $\mathrm{x}_{\mathrm{ij}}, \mathrm{R}_{\mathrm{i}}{ }^{*}$ gives the net

energy at the maximum $\mathrm{x}_{\mathrm{ij}}$. The envelope theorem states that $\partial \mathrm{R}_{\mathrm{i}} / \partial \mathrm{e}_{\mathrm{ij}}=\partial \mathrm{R}_{\mathrm{i}}{ }^{*} / \partial \mathrm{e}_{\mathrm{ij}}=-\mathrm{x}_{\mathrm{ij}}$. (See for example, Varian, 1992.) 